\title{
Estudo Genético nas Distonias Primárias: Recomendações do Grupo de Neurogenética do Centro Hospitalar São João
}

\author{
Genetic Study of Primary Dystonias: Recommendations \\ from the Centro Hospitalar São João Neurogenetics Group
}

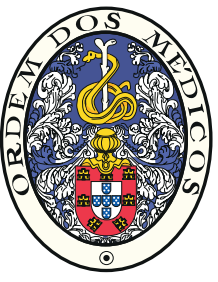

\author{
Ana MONTEIRO $\rrbracket^{1,2}$, João MASSANO ${ }^{1,3}$, Miguel LEÃO ${ }^{4,5}$, Carolina GARRETT ${ }^{1,2}$, em nome do Grupo de Neurogenética \\ do Centro Hospitalar São João \\ Colaboradores do artigo e membros do Grupo de Neurogenética do Centro Hospitalar São João: Carla MOURA ${ }^{5,6}$, \\ Elsa AZEVEDO ${ }^{1,2}$, Joana GUIMARÃES ${ }^{1,2}$, João Paulo OLIVEIRA ${ }^{5,7}$, Pedro CASTRO ${ }^{1,2}$ \\ Acta Med Port 2017 Apr;30(4):340-346 - https://doi.org/10.20344/amp.8622
}

\section{RESUMO}

As distonias primárias são um grupo particular de distonias, de etiologia presumivelmente genética e com sintomas que podem surgir em diversas idades e progredir durante um período variável de tempo. O seu diagnóstico constitui, por isso, um desafio, colocando-se frequentemente na prática clínica a questão da realização do estudo genético. Nos últimos anos foram identificadas várias mutações genéticas causadoras de distonia primária. A escolha do teste molecular é complexa, quer pela especificidade clínica e baixa frequência, quer pelo custo associado ao estudo genético. Esta escolha deve ser feita mediante observação especializada por médicos com elevada diferenciação nesta área, apoiada num plano racional de investigação. O Grupo de Neurogenética do Centro Hospitalar São João (grupo multidisciplinar de Neurologistas e Geneticistas com interesse especial na área das doenças neurogenéticas) delineou recomendações de consenso para a investigação da etiologia genética das distonias primárias, tendo por base documentos de consenso internacionais e a evidência científica entretanto publicada. Este documento adota o novo sistema de nomenclatura para as formas genéticas de doenças do movimento, permitindo a sua utilização padronizada e sistemática na prática clínica.

Palavras-chave: Consenso; Distonia/diagnóstico; Distonia/genética; Portugal

\section{ABSTRACT}

The primary dystonias are a particular group of dystonias of presumed genetic origin, with a wide age of onset and variable progression. The diagnosis is, therefore, a challenge and the issue of the genetic investigation presents frequently in clinical practice. In the past few years several gene mutations have been identified as causative of primary dystonias. The choice of molecular testing is complex, given the clinical specificities and low frequency of these entities and the cost of genetic testing. It must follow observation by specialized clinicians highly differentiated in this area and be supported by a rational plan of investigation. The Centro Hospitalar São João Neurogenetics Group, a multidisciplinary team of Neurologists and Geneticists with special interest in neurogenetic disorders, devised consensus recommendations for the investigation of the genetic etiology of the primary dystonias, based on international consensus documents and recent published scientific evidence. This manuscript adopts the new classification system for genetic movement disorders, allowing for its systematic and standardized use in clinical practice.

Keywords: Consensus; Dystonia/diagnóstico; Dystonia/genetics; Portugal

\section{INTRODUÇÃO}

A distonia é definida como uma doença do movimento hipercinética caracterizada pela contração muscular involuntária, intermitente ou sustentada, causando movimentos repetitivos e/ou posturas anormais. Os movimentos distónicos são tipicamente estereotipados, geralmente em torção ou causando tremor. A distonia é muitas vezes iniciada ou agravada pelos movimentos voluntários, associada a ativação muscular de overflow, podendo surgir apenas em tarefas específicas (p.ex. escrever, tocar um instrumento). Pode afetar um ou mais locais do corpo. ${ }^{1}$

A classificação das distonias tem vindo a evoluir, sendo atualmente classificadas segundo dois eixos: 1 - características clínicas e 2 - etiologia. A razão pela qual se classificam nestes dois eixos advém da necessidade, por um lado, de organizar em grupos clinicamente relevantes para facilitar o diagnóstico e tratamento e, por outro, de organizar o conhecimento biológico e guiar o desenvolvimento de novos conceitos relativos à patogénese e novas terapias. $\mathrm{O}$ primeiro eixo caracteriza as distonias usando quatro dimensões: região corporal afetada, idade de início, aspetos temporais e presença de outras manifestações clínicas. O segundo eixo concentra-se na etiologia, usando duas dimensões: hereditariedade e neuropatologia subjacente. Estes dois eixos não são independentes, devendo ser usados em conjunto. $\mathrm{O}$ eixo 1 permite delinear a fenomenologia clínica e definir um padrão sindrómico para depois ser usado o eixo 2 na busca de causas potenciais e na seleção do estudo genético. No eixo 2 (etiologia) as distonias são categorizadas

1. Departamento de Neurociências Clínicas e Saúde Mental. Faculdade de Medicina. Universidade do Porto. Porto. Portugal.

2. Serviço de Neurologia. Centro Hospitalar São João. Porto. Portugal.

3. Serviço de Neurologia. Hospital Pedro Hispano. Unidade Local de Saúde de Matosinhos. Matosinhos. Portugal.

4. Unidade de Neuropediatria. Serviço de Pediatria. Centro Hospitalar São João. Porto. Portugal.

5. Serviço de Genética. Faculdade de Medicina. Universidade do Porto. Porto. Portugal.

6. Serviço de Otorrinolaringologia. Centro Hospitalar São João. Porto. Portugal.

7. Serviço de Nefrologia. Centro Hospitalar São João. Porto. Portugal.

$\bowtie$ Autor correspondente: Ana Monteiro. ana.mg.monteiro@gmail.com

Recebido: 29 de dezembro de 2016 - Aceite: 06 de março de 2017 | Copyright @ Ordem dos Médicos 2017 
de acordo com a patologia do sistema nervoso central (degenerativas, estruturais ou sem doença degenerativa ou estrutural), a hereditariedade (hereditária ou adquirida) e, nos casos idiopáticos (geneticamente inclassificáveis), em esporádica ou familiar. ${ }^{2}$

Nas distonias primárias os sintomas podem surgir em diversas idades e progredir durante um período variável de tempo. Os exames complementares de diagnóstico (incluindo a neuroimagem) não demonstram alterações, não existindo indicadores sugestivos de neurodegenerescência. Nestes casos coloca-se frequentemente na prática clínica a questão da realização do estudo genético, disponível apenas num número limitado de situações.

A escolha do teste molecular genético para o diagnóstico das distonias é complexa, dadas as especificidades clínicas e a baixa frequência das situações aqui referidas. Assim, esta escolha deve ser feita mediante observação especializada por médicos com elevada diferenciação nesta área. Devem sempre ser excluídas causas secundárias, incluindo ambientais (trauma, hipóxia/anóxia, fármacos, drogas, infeções), doenças neurodegenerativas (atrofia de múltiplos sistemas, degenerescência corticobasal, paralisia supranuclear progressiva, doença de Huntington, doença de Parkinson (sobretudo de início precoce), doenças metabólicas (homocisteinúria, acidúrias orgânicas, citopatias mitocondriais, gangliosidose GM1 e GM2, leucodistrofia metacromática, lipofuscinose neuronal ceróide, etc) e outras doenças heredo-degenerativas (doença de Wilson, aceruloplasminemia, neuroacantocitose, Niemann-Pick tipo $\mathrm{C}$, etc).$^{3}$

Este documento apresenta um protocolo de estudo genético nas distonias primárias de etiologia presumivelmente genética, proposto pelo Grupo de Neurogenética (GNgen) do Centro Hospitalar São João (CHSJ), para utilização padronizada e sistemática na prática clínica.

\section{METODOLOGIA PARA ELABORAÇÃO DO PROTOCOLO}

O GNgen do CHSJ foi formalizado em 2011 com a criação da Consulta de Grupo. Reúne periodicamente para promover a partilha de conhecimento e a discussão clínica e científica no âmbito das doenças neurogenéticas. É constituído por um conjunto definido de profissionais provenientes de diferentes áreas técnico-científicas (vide final do artigo), sendo as reuniões abertas a todos os médicos do CHSJ que nelas queiram participar, podendo levar casos mais complexos para discussão e decisão de estudo genético pelo grupo.

A elaboração do protocolo de estudo genético nas distonias primárias foi atribuída a um núcleo de autores, que realizaram a pesquisa bibliográfica, analisaram a literatura disponível e elaboraram uma primeira versão do protocolo, posteriormente enviada a todos os membros do GNgen por correio eletrónico para recolha de sugestões e críticas. As alterações sugeridas foram discutidas e incorporadas na versão definitiva, que foi apresentada, debatida e aprovada por consenso em reunião do GNgen.

\section{ESTUDO GENÉTICO ETIOLÓGICO NAS DISTONIAS PRIMÁRIAS: RECOMENDAÇÕES CLÍNICAS}

As distonias primárias de etiologia presumivelmente genética, quer isoladas quer associadas a outros sintomas, são de etiologia monogénica com transmissão mendeliana e, frequentemente, têm expressão clínica muito variável, incluindo penetração incompleta. Estas síndromes eram classificadas segundo a designação 'DYT', seguida de um número internacionalmente determinado. Estão atribuídas designações desde DYT1 a DYT27, embora alguns dos loci ainda não tenham sido confirmados. ${ }^{4,5} \mathrm{O}$ número crescente de inconsistências na designação 'DYT' levou à proposta de um novo sistema de nomenclatura para as formas genéticas de doenças do movimento, incluindo as distonias, no qual apenas genes confirmados são incluídos na lista e já não são numerados. Em vez disso, o prefixo 'DYT' é seguido do nome do gene nos casos em que a distonia é a manifestação proeminente (p.ex. DYT-TOR1A em vez de DYT1). Quando caracterizada por mais que uma doença do movimento, deve ser usado um prefixo duplo (p.ex. DYT/ PARK-ATP1A3). ${ }^{6,7}$ Esta nova nomenclatura vem resolver muitos dos problemas identificados no sistema anterior permitido uma organização mais lógica e maior flexibilidade na classificação de novas entidades que entretanto surjam, facilitando a sua utilização na prática clínica.

Este protocolo foi definido a partir das linhas de orientação emitidas pela European Federation of Neurological Societies (EFNS), publicadas em 2011 no European Journal of Neurology, ${ }^{8}$ e atualizado de acordo com as evidências entretanto tornadas disponíveis na literatura científica, seguindo a nova classificação das distonias e a nova classificação das formas genéticas acima descrita. ${ }^{2,5-7,9,10}$

Os níveis de evidência apontados para cada recomendação são os utilizados de forma padronizada a nível internacional. Sempre que não existam dados de Medicina Baseada na Evidência os peritos envolvidos na elaboração destas linhas de orientação emitiram uma recomendação consensual baseada na sua própria experiência e conhecimentos (boa prática clínica). A esta base de trabalho foram acrescentadas alterações adicionais relevantes, decorrentes da evolução do conhecimento científico entretanto ocorrida desde a publicação dos documentos de referência mencionados.

\section{Definição e classificação das distonias primárias}

As distonias primárias com etiologia genética confirmada podem ser divididas clinicamente em (1) distonias isoladas e (2) distonias combinadas. Nas formas com distonia isolada esta é a única manifestação, com a exceção do tremor que pode associar-se à distonia. As distonias combinadas podem ser subdivididas, segundo o padrão temporal, em persistentes ou paroxísticas. As persistentes podem ainda categorizar-se em distonia com parkinsonismo ou com mioclonias (Fig. 1). ${ }^{5,7} \mathrm{Na}$ Tabela 1 estão descritas as distonias com gene identificado. 
Distonias: fenótipos e genótipos

Distonia isolada

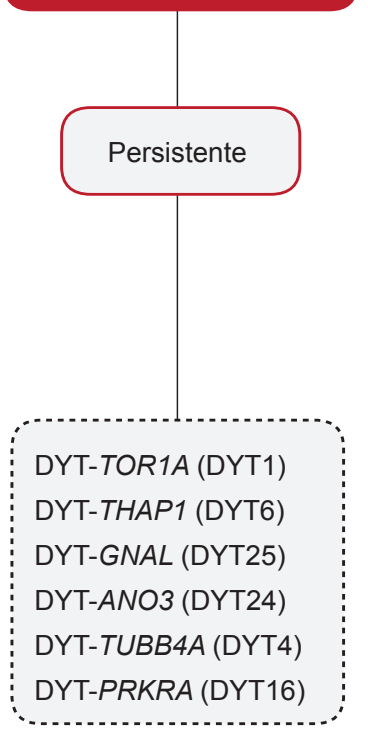

Distonia combinada

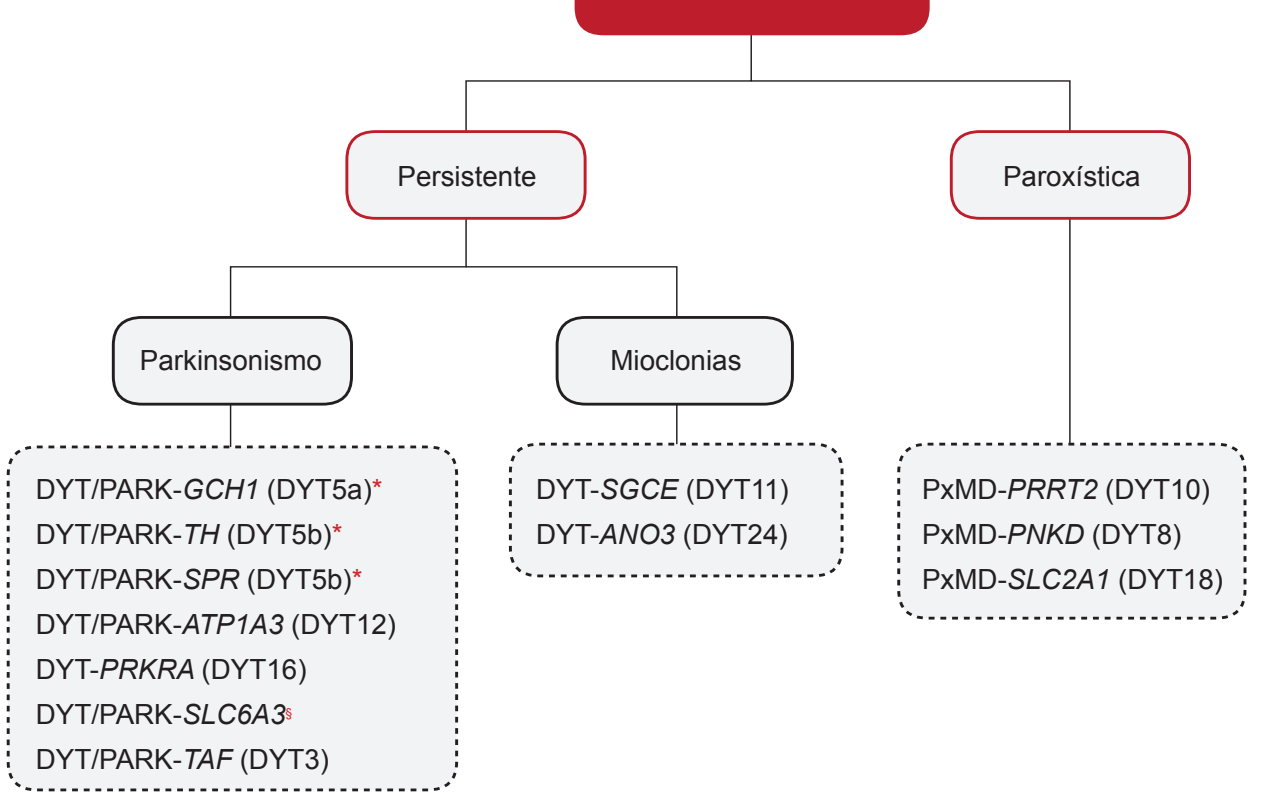

Figura 1 - Organização das distonias segundo os seus fenótipos e genótipos. Adaptado das referências 3 e 11.

* Distonias com resposta à dopa. Nota: a designação de 'distonia isolada' admite também a presença de tremor para além da distonia como característica secundária ou predominante no quadro clínico, mas não de outras alterações clínicas. §: Idade pediátrica; TOR1A: Torsin family 1, member A (torsin A); THAP1: THAP domain-containing protein 1; GNAL: Guanine nucleotide-binding protein; ANO3: Anoctamin 3; TUBB4A: Tubulin beta-4A; PRKRA: Protein kinase, interferon-inducible double-stranded RNA-dependent activator; TAF1: TATA-binding protein-associated factor-1; GCH1: GTP cyclohydrolase I; SPR: Sepiapterine redutase; ATP1A3: Sodium-potassium ATPase, alfa-3 polipeptide; SGCE: Epsilon sarcoglycan; PxMD: Paroxysmal movement disorders; PRRT2: Proline-rich transmembrane protein 2; PNKD: Paroxysmal nonkinesigenic dyskinesia; SLC2A: Solute carrier family 2 (facilitated glucose transporter), member 1.

\section{Recomendações}

As recomendações relativas ao estudo genético etiológico das distonias primárias são $0^{5,8,9}$ :

1. Os testes genéticos devem ser feitos após ser estabelecido o diagnóstico clínico (nível B de evidência). ${ }^{8} \mathrm{~A}$ realização de aconselhamento genético é formalmente recomendada tendo em conta a variabilidade de expressão clínica.

2. Recomenda-se a realização de teste genético para DYT-TOR1A (DYT1) em doentes com distonia primária de início precoce (até aos 30 anos) com atingimento primário dos membros (nível $\mathrm{B}$ de evidência), ${ }^{8}$ bem como naqueles cujos sintomas surgem acima dos 30 anos e que têm um familiar afetado (nível B de evidência). ${ }^{8}$

3. Nas famílias com distonia a realização de teste genético para DYT-TOR1A (DYT1) em indivíduos assintomáticos deve ser realizada no âmbito de um processo de aconselhamento genético (recomendação do GNgen do CHSJ), pois a presença de mutação não implica a existência de sintomas no futuro (penetração incompleta).

4. O teste genético para DYT-THAP1 (DYT6) está recomendado na distonia de início precoce ou na distonia familiar com predomínio crânio-cervical e/ou distonia laríngea (disfonia espasmódica), ou após exclusão de DYT-TOR1A (DYT1) (boa prática clínica ${ }^{8}$ ).

5. Após a exclusão de DYT-TOR1A e DYT-THAP1, recomenda-se o estudo genético para DYT-GNAL (DYT25) em doentes com distonia isolada de início precoce e em doentes com distonia cervical tardia e história familiar consistente com transmissão autossómica dominante (recomendação do GNgen do CHSJ).

6. Nos indivíduos com mioclonias de início precoce, predominantemente de ação, afetando os membros superiores ou pescoço, particularmente se há história consistente com transmissão autossómica dominante e/ou sintomas obsessivo-compulsivos, deve ser feito teste genético (sequenciação seguida de pesquisa de deleções/duplicações) para DYT-SGCE (DYT11) (boa prática clínica). ${ }^{8}$

7. Deve ser oferecida a possibilidade de testar para a presença de mutações DYT-ANO3 (DYT24) aos doentes com distonia mioclónica DYT-SGCE negativa com história familiar de distonia cervical ou distonia com mioclonias, bem como aos doentes com tremor proeminente e distonia ligeira. ${ }^{10-12}$ (recomendação do GNgen do CHSJ). 
Tabela 1 - Distonias com gene identificado e confirmado (1/3)

\begin{tabular}{|c|c|c|}
\hline Gene & Designação & Aspectos clínicos gerais típicos \\
\hline \multicolumn{3}{|l|}{ Distonia isolada } \\
\hline
\end{tabular}

DYT-THAP1 Início na adolescência com (DYT6) fenótipo misto

$\begin{array}{ll}\begin{array}{l}\text { DYT-GNAL } \\ \text { (DYT25) }\end{array} & \begin{array}{l}\text { Segmentar de início no } \\ \text { adulto }\end{array} \\ \begin{array}{l}\text { DYT-ANO3 } \\ \text { (DYT24) }\end{array} & \text { Focal e segmentar } \pm \text { tremor }\end{array}$

DYT-TUBB4A (DYT4)
Focal, segmentar e generalizada
Características de distonia focal e generalizada. Envolvimento mais proeminente dos músculos cervicais, faciais, laríngeos e respiratórios, sendo a disfonia um sintoma frequentemente predominante. Alguns sintomas sobrepõem-se aos da distonia TOR1A, mas idade de início mais tardia (média 19 anos, entre 5 - 38 anos). Hereditariedade: AD com penetração de $40 \%$.

Distonia cervical ou craniana com início geralmente pelos 30 anos, embora varie entre 7 - 63 anos. O fenótipo inclui tremor do braço, início laríngeo ou desenvolvimento de disfonia espasmódica à posteriori. Generalização em $10 \%$ dos casos. Hereditariedade: AD

Descrita mais recentemente em três famílias. Hereditariedade: AD. Início precoce ou na idade adulta (entre os 4 - 40 anos). Apresentação com distonia cervical e tremor. Também observadas distonia laríngea e craniana, bem como distonia ligeira dos membros superiores. Nunca foi descrita distonia generalizada. Tremor como característica-chave, sobretudo cefálico e dos membros superiores, por vezes a preceder a distonia (vide distonia combinada).

Início na adolescência/adulto jovem. Causa rara de distonia isolada. Distonia laríngea proeminente tipo 'disfonia sussurrante' e envolvimento oromandibular, associada a distonia crânio-cervical, segmentar ou generalizada e alteração da marcha peculiar tipo 'hobby horse'. Descrita também forma alélica, por mutação de novo noutras regiões do mesmo gene, causando doença de hipomielinização com atrofia dos gânglios basais e do cerebelo, caracterizada por atraso do desenvolvimento, ataxia cerebelosa, distonia, epilepsia e tetraplegia espástica de início na infância. Hereditariedade: AD. 
Tabela 1 - Distonias com gene identificado e confirmado (2/3)

\begin{tabular}{|c|c|c|}
\hline Gene & Designação & Aspectos clínicos gerais típicos \\
\hline \multicolumn{3}{|l|}{ Distonia combinada } \\
\hline \multicolumn{3}{|l|}{ Persistente } \\
\hline $\begin{array}{l}\text { DYT/PARK-GCH1 } \\
\text { (DYT5a), } \\
\text { DYT/PARK-THe } \\
\text { DYT/PARK-SPR } \\
\text { (DYT5b) }\end{array}$ & $\begin{array}{l}\text { Distonia responsiva à dopa; } \\
\text { doença de Segawa }(\mathrm{GCH} 1)\end{array}$ & $\begin{array}{l}\text { Início de distonia na infância, com flutuação diurna e resposta dramática } \\
\text { à L-dopa; deve fazer-se prova terapêutica em todos os casos de } \\
\text { distonia de início precoce. Mais tarde surge parkinsonismo (raramente, } \\
\text { pode ser a única manifestação). Apresentações atípicas: hipotonia na } \\
1^{\text {a }} \text { semana de vida, alteração da marcha (pode simular paraparésia), } \\
\text { sintomas psiquiátricos; fenótipos complexos mais raros e graves (crises } \\
\text { epilépticas, dificuldades cognitivas...) sobretudo com mutações da } \\
\text { TH e SPR. Portadores da GCH1: alta variabilidade fenotípica intra e } \\
\text { interfamílias; penetração reduzida. Sintomas não-motores associados: } \\
\text { perturbação do sono, do humor e enxaqueca. Hereditariedade: AD para } \\
\text { a GCH1 e AR para a TH e SPR. }\end{array}$ \\
\hline
\end{tabular}

DYT/PARK-ATP1A3 Distonia-parkinsonismo (DYT12) rapidamente progressiva
Distonia-parkinsonismo ligada ao X (doença de Lubag)

Generalizada

(DYT16), parkinsonismo inconsistente

DYT/PARKSLC6A3

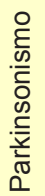

DYT-SGCE (DYT11)
Distonia focal e segmentar associada a tremor
Idade de início variável (infância à sexta década); surgimento abrupto e progressão rápida (horas a semanas) de distonia e parkinsonismo, precipitados por stress físico (febre, fadiga, exercido prolongado, parto, álcool) ou mental. Gradiente rostro-caudal (face $>$ membros superiores $>$ membros inferiores). Os sintomas incluem espasmos distónicos dos membros superiores, distonia orofacial, disartria e disfagia. Por vezes crises epilépticas, distonia paroxística e alterações psiquiátricas. Espectro fenotípico alargado: mutações da ATP1A3 causam $78 \%$ das hemiplegias alternantes da infância. Hereditariedade: AD, penetração reduzida. Muito raro.

Idade de início na idade adulta, descrita apenas em doentes Filipinos com origem nas Ilhas Panay; manifestação com distonia crânio-cervical, dos membros inferiores, membros superiores ou tronco. Os sintomas parkinsónicos podem preceder o surgimento de distonia; alguns casos com envolvimento oromandibular marcado e disfagia. Hereditariedade: ligada ao X, deve ser considerada apenas em indivíduos de ascendência Filipina; apesar de ligada ao $X$ deve ser considerada também em mulheres, dado ter sido descrita em mulheres heterozigóticas para a mutação (provavelmente fruto de inativação do $\mathrm{X}$ ), embora com manifestações menos severas.

Início na infância ou adolescência; surgimento nos membros superiores ou inferiores; envolvimento oromandibular ou laríngeo marcado, podendo manifestar retrocolis ou opistótono. Pode apresentar-se com parkinsonsimo, embora esta manifestação seja menos consistente. Hereditariedade: AR, muito rara.

Apresentação geralmente em lactentes com dificuldade na alimentação, hipotonia e irritabilidade; desenvolvimento progressivo de distonia generalizada e coreia com envolvimento ocular; manifestações parkinsónicas proeminentes desenvolvem-se na infância. Frequentemente não identificada, sendo diagnosticada como paralisia cerebral. O estudo de líquor demonstra um perfil de neurotransmissores com aumento da razão de ácido homovanílico:ácido 5-hidroxindolacético. O espectro fenotípico tem vindo a alargar, sendo agora reconhecidos casos de adultos com parkinsonismo juvenil e precoce. Hereditariedade: AR.

Início na infância ou adolescência precoce. As mioclonias são breves, mais frequentemente do pescoço, tronco e membros superiores. Melhoria dramática mas transitória das mioclonias com álcool. Distonia focal ou segmentar em $50 \%$ (cervical e/ou do escrivão). Membros inferiores raramente afetados. Elevada prevalência de sintomas obssesivos e compulsivos. Osteoporose e atraso do desenvolvimento esquelético: grandes deleções afetando o gene vizinho COL1A2. Hereditariedade: $A D$, penetração reduzida.

Vide descrição na distonia isolada. 
Tabela 1 - Distonias com gene identificado e confirmado (3/3)

\begin{tabular}{|c|c|c|c|}
\hline & Gene & Designação & Aspectos clínicos gerais típicos \\
\hline \multicolumn{4}{|c|}{ Distonia combinada } \\
\hline \multicolumn{4}{|c|}{ Paroxística } \\
\hline \multirow[b]{3}{*}{ 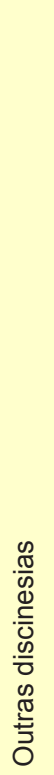 } & $\begin{array}{l}\text { PxMD-PRRT2 } \\
\text { (DYT10) }\end{array}$ & $\begin{array}{l}\text { Distonia/discinésia } \\
\text { paroxística cinesigénica }\end{array}$ & $\begin{array}{l}\text { Início na infância ou adolescência. Despoletada por movimentos } \\
\text { súbitos. Crises com duração de vários minutos, surgem até } 100 \\
\text { vezes por dia. Consistem principalmente em movimentos distónicos } \\
\text { ou coreoatetósicos. Clinica e geneticamente relacionada com outras } \\
\text { patologias, incluindo epilepsia benigna infantil familiar, epilepsia } \\
\text { rolândica, discinesia paroxística induzida pelo exercício e distonia do } \\
\text { escrivão. Hereditariedade: AD }\end{array}$ \\
\hline & $\begin{array}{l}\text { PxMD-PNKD } \\
\text { (DYT8) }\end{array}$ & $\begin{array}{l}\text { Distonia/discinésia } \\
\text { paroxística não-cinesigénica }\end{array}$ & $\begin{array}{l}\text { Situação rara, idade de início variável. Episódios de distonia, coreia ou } \\
\text { balismo que ocorrem geralmente em repouso, envolvendo face, tronco } \\
\text { e membros. Os episódios duram desde alguns minutos até várias } \\
\text { horas; podem ocorrer desde algumas vezes por ano até várias vezes } \\
\text { por dia. Os desencadeantes típicos são: álcool, cafeína, tabaco, stress, } \\
\text { emoções, fadiga e fome. Hereditariedade: AD }\end{array}$ \\
\hline & $\begin{array}{l}\text { PxMD-SLC2A1 } \\
\text { (DYT18) }\end{array}$ & $\begin{array}{l}\text { Distonia/discinésia } \\
\text { paroxística induzida pelo } \\
\text { exercício }\end{array}$ & $\begin{array}{l}\text { Início na infância. Episódios de distonia, coreia ou balismo que surgem } \\
\text { nas regiões excessivamente exercitadas. Membros inferiores afetados } \\
\text { mais frequentemente. Episódios desde alguns minutos até uma } \\
\text { hora, após exercício físico prolongado. Podem ter também epilepsia } \\
\text { (ausências ou CTCG), enxaqueca, défice cognitivo, anemia hemolítica, } \\
\text { ataxia, espasticidade ou atraso do desenvolvimento. Hereditariedade: } \\
\text { AD }\end{array}$ \\
\hline
\end{tabular}

gene ATP1A3 (DYT12) ${ }^{11}$ (recomendação do GNgen do CHSJ).

13. Em doentes com distonia generalizada e parkinsonismo de início precoce, sem resposta à levodopa, poderá ser considerado o teste para DYT-PRKRA (DYT16), uma causa potencialmente sub-reconhecida de distonia-parkinsonismo. ${ }^{11}$ Este gene poderá ser considerado nos casos ATP1A3 negativos (recomendação do GNgen do CHSJ).

14. Recomenda-se o estudo genético para PxMD-PNKD (DYT8) em todos os doentes com quadro clínico de discinésia paroxística não-cinesigénica (boa prática clínica). ${ }^{8}$

15. Recomenda-se o estudo genético de PxMD-PRRT2 (DYT10) e PxMD-SLC2A1 (DYT18) em doentes com discinésias paroxísticas induzidas pelo movimento ou pelo exercício físico, respectivamente. ${ }^{5}$

16. O estudo genético para DYT/PARK-TAF1 (DYT3), uma distonia combinada com parkinsonismo de transmissão ligada ao X, deve apenas ser considerado em pessoas de ascendência Filipina (em particular se tiverem origem familiar nas Ilhas Panay), dado que esta causa genética foi descrita apenas em doentes com esta origem (recomendação do GNgen do CHSJ). ${ }^{5,14}$

17. Atendendo à epidemiologia genética deste grupo de doenças, à necessidade de rapidez de confirmação diagnóstica, nomeadamente para aplicação em diagnóstico pré-natal, e à relação custo-benefício dos testes em causa, pode ser ponderada a realização de painel de estudo multigénico, após a realização de estudos moleculares dirigidos para DYT-TOR1A, DYT-THAP1, DYT/PARK-GCH1 e DYT-SGCE (recomendação do
GNgen do CHSJ).

18. A realização de testes genéticos depende da verificação do cumprimento das recomendações constantes dos pontos anteriores e obedece às disposições legais em vigor (Decreto-Lei n. ${ }^{0} 131 / 2014$, de 29 de Agosto), nomeadamente no que se refere ao diagnóstico pré-sintomático.

19. Este protocolo será revisto sempre que seja entendido necessário e oportuno.

\section{CONSIDERAÇÕES FINAIS}

O número cada vez maior de genes identificados como causa das síndromes distónicas acarreta desafios de diagnóstico, sendo cada vez mais importante a classificação fenotípica cuidada. Esta classificação é extremamente importante no reconhecimento de formas particulares de distonia e pode ser a chave para guiar o diagnóstico, inclusivamente para direcionar o estudo genético. A nova classificação das distonias reforça a importância das características clínicas, que deve ser sempre o ponto de partida para definir a investigação dos doentes. Novas descobertas auxiliadas pelos avanços tecnológicos, como o whole exome sequencing, poderão levar a um melhor conhecimento da fisiopatologia da distonia e ao desenvolvimento de novas terapias, pelo que a correta identificação dos doentes poderá ser cada vez mais pertinente. O uso de 'painéis' comerciais de genes poderá vir a ser uma ferramenta extremamente útil e economicamente mais viável, mas a complexidade do estudo genético nas distonias requer uma observação especializada por profissionais altamente diferenciados nesta área. 


\section{PROTECÇÃO DE PESSOAS E ANIMAIS}

Os autores declaram que os procedimentos seguidos estavam de acordo com os regulamentos estabelecidos pelos responsáveis da Comissão de Investigação Clínica e Ética e de acordo com a Declaração de Helsínquia da Associação Médica Mundial.

\section{CONFIDENCIALIDADE DOS DADOS}

Os autores declaram ter seguido os protocolos do seu centro de trabalho acerca da publicação de dados.

\section{REFERÊNCIAS}

1. Albanese A, Bhatia K, Bressman SB, Delong MR, Fahn S, Fung VS, et al. Phenomenology and classification of dystonia: a consensus update. Mov Disord. 2013;28:863-73.

2. Jinnah HA, Albanese A. The new classification system for the dystonias: why was it needed and how was it developed? Mov Disord Clin Pract. 2014;1:280-4

3. Fung VS, Jinnah HA, Bhatia K, Vidailhet M. Assessment of patients with isolated or combined dystonia: an update on dystonia syndromes. Mov Disord. 2013;28:889-98.

4. Jochim A, Zech M, Gora-Stahlberg G, Winkelmann J, Haslinger B. The clinical phenotype of early-onset isolated dystonia caused by recessive COL6A3 mutations (DYT27). Mov Disord. 2016;31:747-50.

5. Klein C. Genetics in dystonia. Parkinsonism Relat Disord. 2014;20:S13742.

6. Marras C, Lohmann K, Lang A, Klein C. Fixing the broken system of genetic locus symbols: Parkinson disease and dystonia as examples. Neurology. 2012;78:1016-24

7. Marras C, Lang A, van de Warrenburg BP, Sue CM, Tabrizi SJ, Bertram L, et al. Nomenclature of genetic movement disorders: Recommendations of the international Parkinson and movement disorder society task force. Mov Disord. 2016;31:436-57.

\section{CONFLITOS DE INTERESSE}

Os autores declaram não terem qualquer conflito de interesse relativamente ao presente artigo.

\section{FONTES DE FINANCIAMENTO}

Este trabalho não foi subsidiado por quaisquer fundos provenientes de entidades no domínio público ou privado.

8. Albanese A, Asmus F, Bhatia KP, Elia AE, Elibol B, Filippini G, et al. EFNS guidelines on diagnosis and treatment of primary dystonias. Eur $\mathrm{J}$ Neurol. 2011;18:5-18.

9. Moghimi N, Jabbari B, Szekely AM. Primary dystonias and genetic disorders with dystonia as clinical feature of the disease. Eur J Paediatr Neurol. 2014;18:79-105.

10. Balint B, Bhatia KP. Dystonia: an update on phenomenology, classification, pathogenesis and treatment. Curr Opin Neurol. 2014;27:468-76.

11. Balint B, Bhatia KP. Isolated and combined dystonia syndromes - an update on new genes and their phenotypes. Eur J Neurol. 2015;22:6107.

12. Stamelou M, Charlesworth G, Cordivari C, Schneider SA, Kag G, Sheerin UM. The phenotypic spectrum of DYT24 due to ANO3 mutations. Mov Disord. 2014;29:928-34.

13. $\mathrm{Ng} \mathrm{J}$, Heales SJ, Kurian MA. Clinical features and pharmacotherapy of childhood monoamine neurotransmitter disorders. Paediatr Drugs. 2014;16:275-91.

14. Evidente VG. X-linked dystonia-parkinsonism. In: Pagon RA, Adam MP, Ardinger HH, Wallace SE, Amemiya A, Bean LJ, et al, editors. GeneReviews(R). Seattle: University of Washington; 1993. 